ISSN: $2317-8957$

\title{
ESTUDO DA ADIÇÃO DE AREIA ARTIFICIAL DE SEROPÉDICA NA FLUIDEZ E RESISTÊNCIA DO CONCRETO LEONARDO MOREIRA LIMA ${ }^{1}$, ALEX DA SILVA SIRQUEIRA ${ }^{1}$
}

${ }^{1}$ Laboratório de Engenharia de Polímeros e de Aplicações Industriais, Fundação Centro Universitário Estadual da Zona Oeste

\begin{abstract}
RESUMO
Areia artificial, gerada na fabricação de agregados miúdos de britagem, têm sido cada vez mais utilizada na produção de concretos, em substituição aos agregados miúdos naturais. Fato que, sugere uma forte necessidade do desenvolvimento de estudos sobre a viabilidade técnica em substituir a areia natural pela areia de britagem na produção de concreto em centrais dosadoras. O potencial crescente do mercado pela demanda de areia de britagem tem incentivado os fabricantes de agregados a buscar melhorias para os seus produtos. Visando um melhor entendimento das características dos agregados miúdos nas características do concreto fresco e rígido, este trabalho analisou agregados miúdos de britagem da região de Seropédica, sendo o principal objetivo do programa experimental, analisar a influência desta adição nas propriedades do concreto. Para tal, as principais propriedades avaliadas em concretos e argamassas foram consistência e resistência à compressão. O pó de pedra estudado possui todas as características necessárias à sua utilização para compor, juntamente com a areia natural, a faixa granulométrica apontada como ótima pela NBR 7211 .
\end{abstract}

Palavras-chave: Areia de britagem, areia natural, concreto, agregado, consistência e resistência à compressão.

\begin{abstract}
Artificial sand, generated in the manufacture of fine aggregates crushing, has been increasingly in the production of concrete, replacing the natural fine aggregates. In fact, there is a great need for development and studies on the technical feasibility of replacing natural sand in crushing sand in the production of concrete in metering plants. The increasing market potential for artificial sand has encouraged aggregate manufacturers to seek improvements for their products. Aiming at a better understanding of the characteristics of the small aggregates in the characteristics of fresh and rigid, this work reported fine aggregates of crushing of the region of Seropédica city, being the main objective of the experimental program, to analyze the influence of this addition on the concrete properties. For this, the main properties evaluated in concrete and mortars were consistency and compression strength.
\end{abstract}

Keywords: Artificial sand, Natural sand, concrete, aggregate, consistency and compression strength.

\section{INTRODUÇÃO}

Concreto é o material construtivo de grande aceitação pela sociedade, podendo ser encontrado em casas, estádios, edifícios, rodovias sob a forma de pavimento rígido, pontes, obras de saneamento, bases e torres de energia eólica. Segundo MEHTA \& MONTEIRO (2008) o ma- terial de construção mais utilizado no mundo é o concreto, com consumo estimado em 11 bilhões de toneladas métricas ao ano, não havendo material mais consumido pela humanidade em quantidade, com exceção da água. Dentre os principais componentes utilizados na produção do concreto estão os agregados, que estão subdi- 
vididos em agregado graúdo e agregado miúdo.

De acordo com a norma NBR 7211 (ABNT, 2009), agregado miúdo é resultado da britagem de rochas estáveis, cujas partículas passam pela peneira com abertura de malha de $4,75 \mathrm{~mm}$ e ficam retidos na peneira de $75 \mu \mathrm{m}$, são materiais granulares, geralmente inertes e com dimensões e propriedades adequadas para o uso em diversas aplicações na construção civil.

Os agregados estão entre os materiais mais consumidos em todo mundo, deste modo, uma busca por materiais alternativos com potencial para substituir os agregados, em particular o agregado miúdo de origem natural, mesmo que parcialmente pelo agregado miúdo de britagem, tem motivado um número cada vez maior de pesquisadores CUCCHIERATO (2000). Neste sentido, a aplicação de areia de britagem em concreto, tem se mostrado uma alternativa promissora, proporcionando benefícios à construção civil $\mathrm{e}$ ao meio ambiente, o que sugere uma união vantajosa, porém, pode produzir diferentes efeitos no concreto dos produzidos pela areia natural, em especial nas propriedades no estado fresco, como diminuição da plasticidade e aumento na demanda de água. Isso ocorre, pois a britagem, em geral, confere ao material uma maior porcentagem de material pulverulento - dimensões inferiores a $75 \mu \mathrm{m}$. A textura e a forma dos grãos é outro fator que pode colaborar para a modificação das características do concreto no estado fresco (ALMEIDA, 2005).

Uma análise da literatura, sugere que a utilização de britadores mais modernos do tipo "VSI" (Vertical Shaft Impact - britadores de impacto de eixo vertical). Estes podem minimizar o teor de material pulverulento gerado, visto que estes equipamentos são capazes de produzir agregados com grãos mais esféricos e arredondados, aproximando a areia de britagem do material extraído dos rios. Diferentemente, é observado no processo atual, devido à natureza geológica da região que conduz a formação de grãos lamelares pelos processos de britagem convencionais.
O estudo experimental realizado neste trabalho buscou evidenciar a potencialidade da substituição do agregado miúdo produzido na região metropolitana do Rio de Janeiro por pó de pedra da mesma região na composição do concreto.

\section{MATERIAIS E MÉTODOS}

A metodologia para a obtenção do concreto será essencialmente empírica, uma vez que se pretende evidenciar o desempenho do concreto a partir de diferentes substituições de agregados miúdo natural por agregado artificial, fixando a trabalhabilidade do concreto fresco e a classe de resistência aos 28 dias de idade.

Para isso, foram feitas as seguintes determinações:

Caracterização do agregado graúdo e miúdo, verificação das propriedades do concreto no estado fresco (NBR NM 67:98) e propriedades no estado rígido. Na Tabela 1 encontramse as formulações utilizadas neste estudo.

Tabela 1: Potenciais de substituição da areia natural por pó de pedra

$\begin{array}{cc}\text { Porcentagem de substituição (\%) } & \text { Dosagem } \\ 0 & \text { A } \\ 10 & \text { B } \\ 20 & \text { C } \\ 30 & \text { D } \\ 40 & \text { E } \\ 50 & \text { F }\end{array}$

Para o desenvolvimento da pesquisa, foi utilizado o cimento de alto forno (CP III 40-RS), por se tratar de um material de fácil disponibilidade no mercado da região Sudeste do Brasil. Sua principal ocorrência está ligada a aplicações onde é requerido maior controle do calor de hidratação, bem como resistência a ataques por sulfatos, podendo ainda ser aplicado em diversas obras onde não há solicitações em baixas idades.

A dosagem utilizada de aditivo plastificante no concreto com pó de pedra, nesta etapa do trabalho foi definida com apoio do fabrican- 
te, para aumentar o índice de consistência do concreto, mantendo a demanda d'água. Dentre os benefícios esperados com a utilização deste aditivo, destaca-se a redução da água e a melhoria da trabalhabilidade do concreto.

\section{Moldagem dos Corpos de Prova}

A moldagem dos corpos de prova seguiram os padrões estabelecidos pela NBR 5738 , foram moldados 240 corpos de prova, sendo 40 corpos de prova para o traço referência e 200 para as demais composições $(10 \%$, $20 \%, 30 \%, 40 \%$ e $50 \%$ ), a Figura 1 retrata uma das baterias de testes.

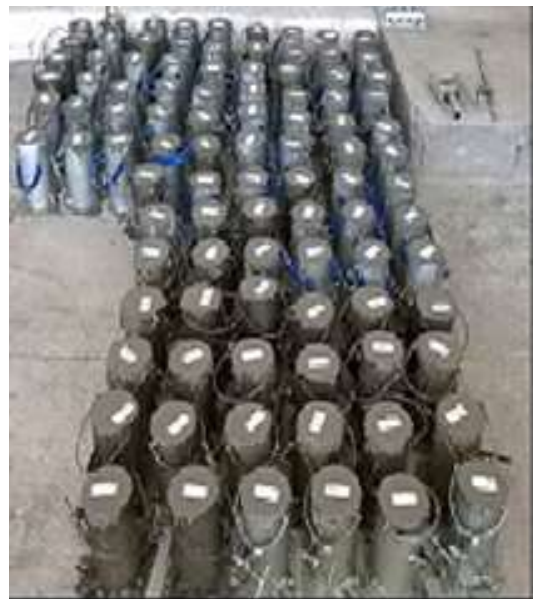

Figura 1: Moldagem dos corpos de prova como descrito pela NBR 5738.

\section{Ensaio de consistência}

Os ensaios de consistência foram realizados seguindo as recomendações da NBR NM 67 , todos os traços tiveram a faixa de trabalhabilidade fixa em $10 \pm 2 \mathrm{~cm}$, a Figura 2 mostra o ensaio com dispositivo adaptado para melhor entendimento do adensamento do material estudado.

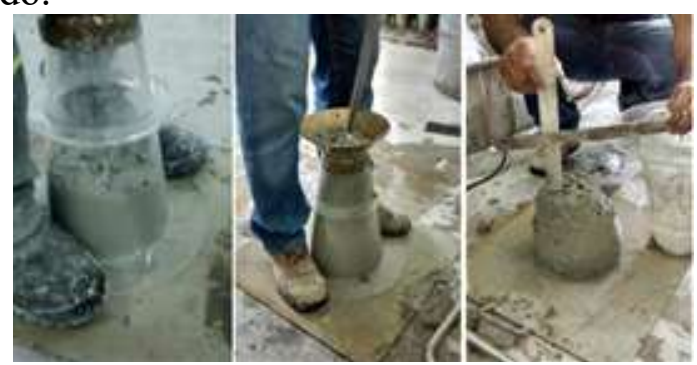

Figura 2: Ensaio de consistência pelo método de Slump;

\section{RESULTADOS E DISCUSSÕES}

\section{Caracterização dos Materiais}

A caracterização dos materiais foi de grande importância no estudo para a substituição parcial de areia natural, visto que este parâmetro exerce grande influência nas propriedades e características dos concretos. A Figura 3 apresenta os resultados da curva granulométrica, normatizados pela NBR 7211:2009, para utilização em concretos. A faixa ótima de utilização, limites inferiores e superiores estão definidos nas linhas tracejadas para cada abertura de peneira. Com base na figura nota-se que para a amostra sem substituinte, somente a peneira com 1,2 $\mathrm{mm}$ enquadra-se na faixa ótima. A caracterização da dosagem $\mathrm{C}$, percentagem de substituição de $20 \%$, nota-se tendência de proximidade da zona ótima para agregados miúdos, salvo apenas pela fração mais grossa de $2,4 \mathrm{~mm}$, que não se aproximou nem mesmo do limite inferior. A caracterização da dosagem $\mathrm{D}$ atende em três peneiras as exigências da zona ótima para agregados miúdos, o módulo de finura, apresentado na Tabela 2, corrobora de forma inversa ao incremento na dosagem. Este comportamento sugere a justificativa de uma melhor distribuição entre as partículas graúdas e miúdas para a dosagem D. A caracterização da dosagem E se encontra quase toda dentro da zona ótima para agregados miúdos, salvo apenas pela fração mais grossa de $2,4 \mathrm{~mm}$. A dosagem $\mathrm{F}$ também se encontra quase toda dentro da zona ótima para agregados miúdos, apresentando certa aproximação da fração mais grossa da zona ótima, no entanto, o concreto produzido com a Dosagem F apresentou um aspecto "pesado", característica que sugere um limite para adição de areia artificial. Possivelmente um aditivo mais robusto permita um incremento maior desta areia artificial, tal adição não foi avaliada neste trabalho. 


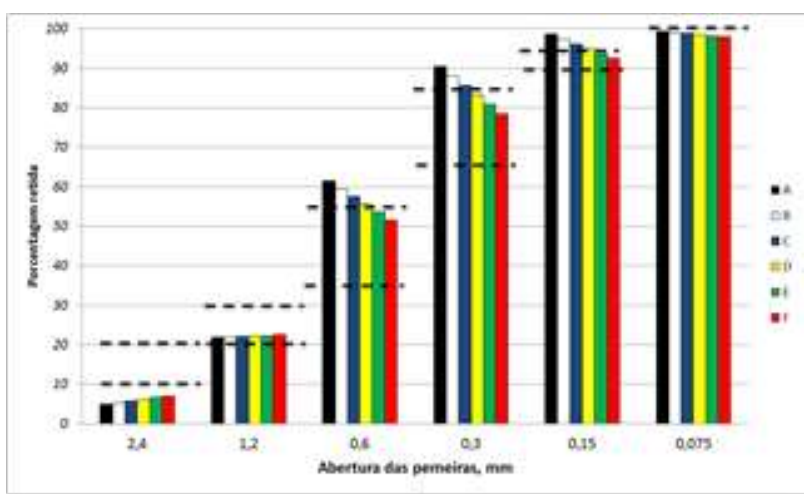

Figura 3. Resultados da curva granulométirca

Tabela 2. Módulo de finura

\begin{tabular}{|c|c|c|}
\hline Amostra & $\begin{array}{c}\text { Percentual de } \\
\text { areia artificial }\end{array}$ & $\begin{array}{c}\text { Módulo de } \\
\text { finura }\end{array}$ \\
\hline A & 0 & 2,77 \\
\hline B & 10 & 2,72 \\
\hline C & 20 & 2,67 \\
\hline D & 30 & 2,62 \\
\hline E & 40 & 2,57 \\
\hline F & 50 & 2,52 \\
\hline
\end{tabular}

A Tabela 3 apresenta o slump obtido para as amostras estudadas. Nota-se que a substituição da areia natural pela areia artificial, provoca desvios (superiores e inferiores) nos valores de slump. Porém, ao analisar o desvio padrão para razão água /cimento $(\mathrm{A} / \mathrm{C})$, nota-se que os traços realizados estavam em conformidade com a norma (permite variação de $2 \mathrm{~cm}$ ) Ao comprar os resultados com a dosagem A, adotada como referência do trabalho, a dosagem que apresentou maior desvio de slump foi para a dosagem $\mathrm{D}$, na razão de água/cimento de 0,55 .

Tabela 3. Slump das amostras

\begin{tabular}{|ccccccc|c|}
\hline \multicolumn{7}{|c|}{ Slume } & \multirow{2}{*}{$\begin{array}{c}\text { Deswio } \\
\text { padrão }\end{array}$} \\
\cline { 1 - 7 } A C & A & B & C & D & F & E & \\
\hline 0,45 & 12,0 & 10,0 & 8,0 & 10,0 & 10,0 & 11,5 & 1,4 \\
\hline 0,55 & 12,0 & 10,0 & 10,0 & 8,8 & 10,0 & 10,5 & 1,0 \\
\hline 0,65 & 10,0 & 10,0 & 11,0 & 10,5 & 10,0 & 10,0 & 0,4 \\
\hline 0,75 & 11,0 & 9,0 & 9,5 & 10,0 & 11,0 & 11,0 & 0,9 \\
\hline
\end{tabular}

$\mathrm{Na}$ construção das curvas de Abrams foi utilizado uma família de traços A-E, com faixa de abatimento em $10 \pm 2 \mathrm{~cm}$, iniciando-se pela dosagem, apresentado pela Figura 4.

Com o auxílio da Figura 4-A, que evidencia o abatimento alcançado pelas famílias de dosagem A, pode-se verificar que todas apresentaram o abatimento esperado, nada mais justo por se tratar de traços de referência, vale evidenciar ainda que todas as quatro amostras avaliadas tiveram a quantidade de água fixa em 190L. A caracterização desta dosagem não mostra diferenças significativas na composição dos finos quando analisada apenas pela zona utilizável determinada pela NBR 7211, como ilustrada na Figura 3, no entanto, a contribuição da parte fina presente na areia artificial, mais precisamente o material passante na peneira $0,075 \mathrm{~mm}$ (material pulverulento), contribuiu para um concreto com maior compacidade e resistência mecânica. Esta contribuição das partículas finas, pode ser evidencia pela dosagem B, Figura 4-B, o preenchimento dos vazios deixados na estrutura pelas partículas graúdas, foi reduzido, deixando um menor espaço para a água. $\mathrm{E}$ a trabalhabilidade foi mantida no intervalo desejado com expresso pela Tabela 3 . De forma semelhante, a curva de Abrams para a dosagem C, Figura 4-C, mostra aumento no preenchimento dos vazios deixados na estrutura pelas partículas graúdas, e neste caso em particular, permitindo uma redução de consumo de cimento caso fosse o objetivo deste trabalho, analogamente a Dosagem B, a trabalhabilidade foi mantida no intervalo desejado, sendo comprovado pela Tabela 3. Fica evidenciado o aumento significativo na demanda d'água para o traço de $\mathrm{A} / \mathrm{C}$ de 0,45 , o que já era esperado devido a maior presença de finos na mistura.

Mesmo apresentando pequenos desvios no FcK 35 e 20, evidenciados pela Figura 4-D, todos traços atendem a resistência característica demandada e o objetivo se mantém em ambos os parâmetros estabelecidos, resistência e trabalhabilidade. . Mesmo apresentando resultados mais homogêneos para resistências a compressão das idades de 28 dias, na dosagem E , 
houve pequena queda quando comparado ao traço referência, sendo novamente nos teores A/ Cs mais elevados, e com todos traços atendendo a resistência característica demandada. A mesma homogeneidade se observou na trabalhabilidade, que segundo Carneiro (1999), se deve a otimização do empacotamento, que favorece o deslizamento das partículas maiores entre os menores. Para a dosagem F, os resultados de resistências a compressão das idades de 28 dias e a trabalhabilidade se mostraram mais homogêneos, com pequena redução de resistência nos traços de menor consumo de cimento e $\mathrm{A} / \mathrm{Cs}$ mais elevados, porém, todos traços estudados atenderam a resistência característica demandada, como representado pela Figura 4-3.

(A)

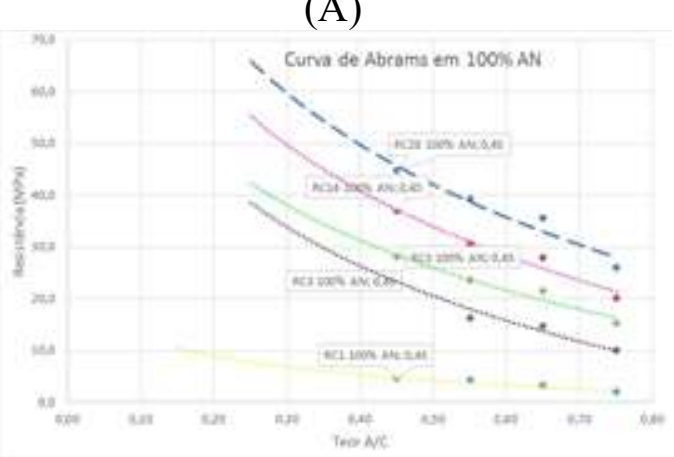

(B)

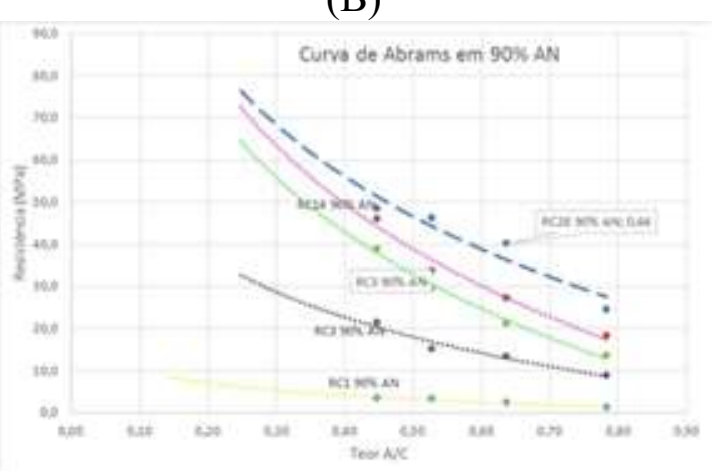

(C)

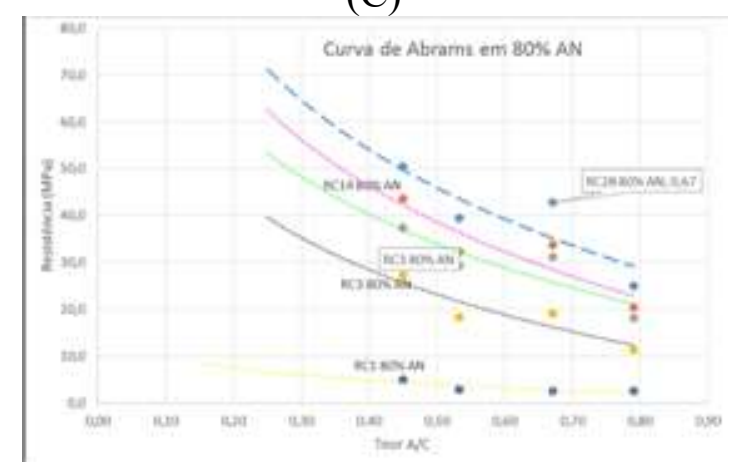

(D)

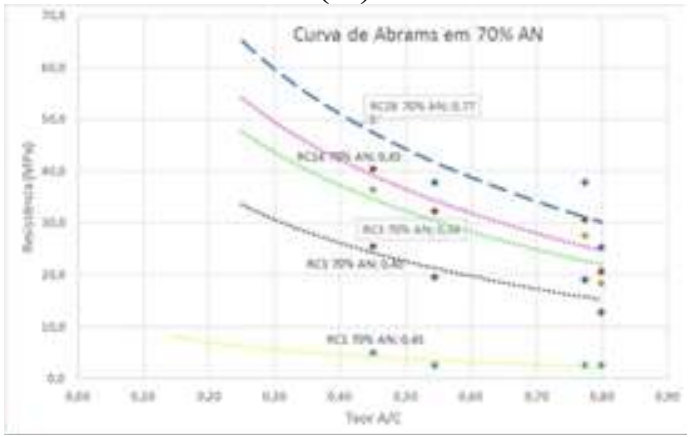

(E)

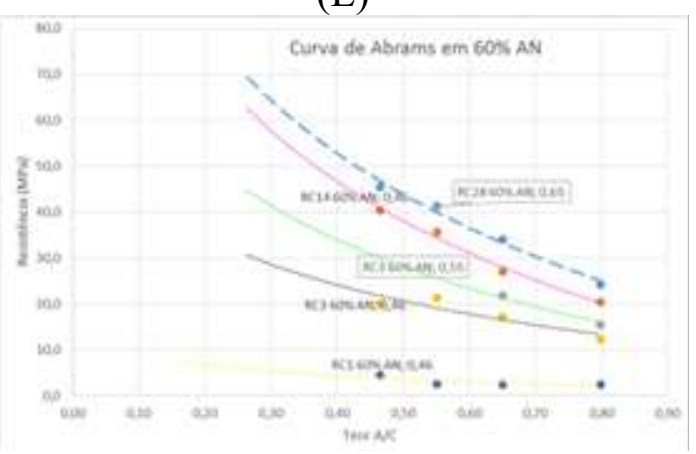

(F)

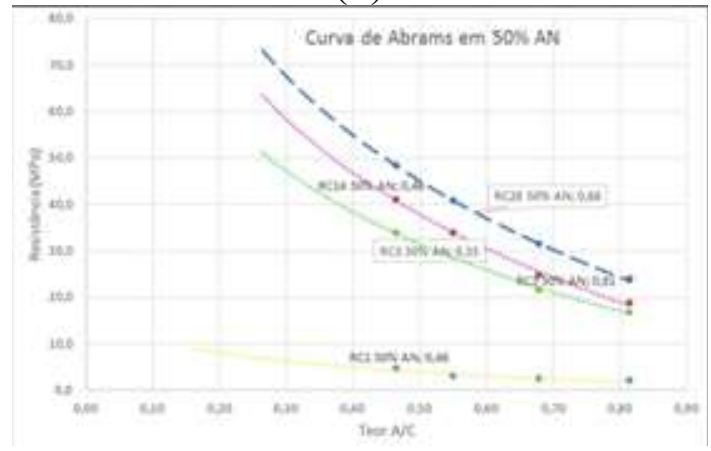

Figura 4. Curva de Abrams para as dosagem A, B, C, D, E e F.

\section{Conclusões}

De modo geral, os resultados obtidos nos experimentos realizados com areia artificial de granito gnaisse, em substituição parcial à areia natural de rio, para produção de concretos, permitiram concluir que as etapas propostas obtiveram sucesso, demonstrando a viabilidade e as vantagens da substituição da areia natural pelo pó de pedra nos concretos estudados, limitandose ao teor máximo de $50 \%$ de substituição.

Permitem ainda apontar que além dos avanços financeiros que a substituição pode proporcio- 
nar, a principal vantagem ao uso do pó de pedra, está relacionada ao aspecto ambiental, uma vez que sua utilização, mesmo que parcial, significa uma considerável redução aos danos causados pela extração da areia natural e a eliminação do passivo gerado pelas empresas produtoras de agregado.

Num olhar mais específico, os resultados apresentados, em substituição parcial à areia natural, para produção de concreto, permitiram concluir que:

O pó de pedra estudado possui todas as características necessárias à sua utilização para compor, juntamente com a areia natural, a faixa granulométrica apontada como ótima pela NBR 7211. A areia natural normalmente utilizada para confecção de concreto na região estudada, apresentou uma dimensão máxima característica $2,4 \mathrm{~mm}$ e um módulo de finura de 2,77 , que combinado ao pó de pedra com dimensão máxima característica de $4,8 \mathrm{~mm}$ e módulo de finura igual a de 2,27 , resultou em um melhor empacotamento.

\section{REFERÊNCIAS}

ALMEIDA, I. R. Concretos dosados em central, com areia $100 \%$ artificial. In: Anais do II SUFFIB - SEMINÁRIO: O uso da fração fina da britagem. São Paulo, 2005.

ASSOCIAÇÃO BRASILEIRA DE NORMAS TÉCNICAS. NBR 5738: C Concreto - Procedimento para moldagem e cura de corpos de prova. Rio de Janeiro, 2015.

ASSOCIAÇÃO BRASILEIRA DE NORMAS TÉCNICAS. NBR 7211: Agregados para concreto - Especificação, Rio de Janeiro, 2009.

ASSOCIAÇÃO BRASILEIRA DE NORMAS TÉCNICAS. NBR NM 67: Concreto - Determinação da consistência pelo abatimento do tronco de cone. Rio de Janeiro, 1998

CARNEIRO, ARNALDO MANOEL PEREIRA., Dosagem de Argamassas através de cusrvas granulométricas / A.M.P. Carneiro, M.A. Cincotto. - São Paulo: EPUSP, 1999. 14 p. - (Boletim Técnico da Escola Politécnica da USP, Departamento de Engenharia de Construção Civil, BT/PCC/237)

CUCHIERATO, Gláucia. Caracterização tecnológica de resíduos da mineração de agregados da Região metropolitana de São Paulo (RmsP), visando seu aproveitamento econômico. 2000. Tese de Doutorado. Universidade de São Paulo.

MEHTA, P. K.; MONTEIRO, P. J. M. Concreto Microestrutura, Propriedade e Materiais $-3^{a}$ edição. São Paulo Ed.:IBRACON 2008. ISBN.: 978-85-98576-12-1. 